\title{
Effect of graphene nanoplatelets on flame retardancy and corrosion resistance of epoxy nanocomposite coating
}

\author{
Siti Maznah Kabeb a , Azman Hassan ${ }^{\text {b, }}{ }^{,}$, Zurina Mohamad b, Zalilah Sharer ${ }^{\text {b }}$, Munira Mokhtar \\ b, Faiz Ahmad ${ }^{\mathrm{C}}$ \\ ${ }^{a}$ Faculty of Industrial Sciences \& Technology, Universiti Malaysia Pahang, Lebuhraya Tun Razak, 26300 Gambang, Kuantan, Pahang \\ ${ }^{b}$ Department of Bioprocess and Polymer Engineering, Faculty of Chemical and Energy Engineering, Universiti Teknologi Malaysia, Skudai 81310, \\ Johor, Malaysia \\ c Department of Mechanical Engineering, Universiti Teknologi Petronas, 32610 Seri Iskandar, Perak \\ * Corresponding author: azmanh@cheme.utm.my
}

Article history

Received 24 January 2019

Revised 5 Mac 2019

Accepted 26 July 2019

Published Online 25 August 2019

\begin{abstract}
Various concentrations of graphene nanoplatelets (GNP) i.e. $0.2,0.4,0.6,0.8$ and 1.0 wt. \% were incorporated into the epoxy resin by sonication technique and mechanical agitation process. Limiting oxygen index (LOI) test and thermogravimetric analysis (TGA) indicated that the presence of GNP greatly enhanced the flame retardancy properties of the epoxy coating. Salt spray results obtained suggested that the addition of GNP enhanced corrosion performance and reducing the water absorption in comparison with pristine epoxy coating. Adhesion (cross-cut test) revealed that the presence of GNP showed great adhesion to substrates. Incorporation of 0.8 wt. \% GNP exhibited the superior anticorrosion performance, great adhesion to subtract, and the lowest water uptake among other samples.
\end{abstract}

Keywords: Epoxy, nanocomposites, coatings, graphene nanoplatelets

\section{INTRODUCTION}

Epoxy coatings have been developed over the years due to their good barrier properties that can protect metals from corrosion over long periods of time (Pour-Ali et al., 2014; Atta et al., 2015). However, pristine epoxy coatings have low durability as anticorrosion coating due to the presence of holes and defects which are permeable to oxygen, water, and corrosive ions such as $\mathrm{Cl}^{-}, \mathrm{H}^{+}$, and $\mathrm{SO}_{2}{ }^{-4}$ (Popović et al., 2005). Therefore, numerous types of additives have been employed to improve the barrier performance of these polymeric coatings (Zhang et al., 2007; Shao et al., 2009; Chen et al., 2017). The incorporation of fine particles that are miscible into epoxy resin can occupy cavities by reducing the porosity and zigzagging the diffusion path for deleterious species and consequently enhance the integrity and durability of coatings (Shi et al., 2003; Hartwig et al., 2005).

Graphene related material have attracted tremendous attention in various potential applications including batteries (Raccichini et al., 2015), capacitors (Xia et al., 2015), nanocomposites (Mittal et al., 2015), sensors (Vashist et al., 2015), and coatings for corrosion prevention (Chen et al., 2017; Prasai et al., 2012). These applications are possible due to its unique structures and extraordinary electronic, thermal, mechanical, and barrier properties. Previous studies have indicated that graphene-based coatings possess excellent anticorrosion barriers for metals (Kirkland et al., 2012; Chang et al., 2012; Zhou et al., 2013; Yu et al., 2014). Kirkland et al. (2012) reported that the electrochemical response of graphene-coated nickel and copper, where the graphene layer was able to improve the anticorrosion performance of pure metals. The capability of graphene to enhance oxidation resistance was demonstrated by Chen et al. (2011). It helps to create an air-tight "balloon" that presumably increase barrier properties and impermeability to oxygen (Bunch et al., 2008).

To the best of our knowledge, not many studies investigate the effect of graphene on corrosion performance and flame retardancy of epoxy nanocomposite coating. One related study by Alhumade et al. (2016) revealed the effect of different graphene nanosheets (GNS) loading on corrosion performance of stainless-steel Type 304. They found that low graphene loading up to $0.5 \mathrm{wt}$ \% boost up the life cycle of stainless-steel substrates due to the barrier property of graphene, which limits the diffusion of corrosive agents to reach the metal substrates. Nevertheless, the effect of GNS on flame retardancy was not discussed and highlighted in their study.

In this work, epoxy resin type BE-188 and GNP nanofiller were prepared by stirring and bath sonication before coated on the mild steel plate. The anticorrosion performance and flame retardancy properties of epoxy filled GNP nanocomposite coatings were evaluated by salt spray and LOI test, respectively.

\section{EXPERIMENTAL}

\section{Materials}

The mild steel plate which was readily sandblasted was cut into dimensions of $100 \mathrm{~mm} \times 50 \mathrm{~mm} \times 1.5$. For salt spray and adhesion tape test, they were coated with epoxy-filled graphene nanocomposite coating. The diglycidyl ether of bisphenol A (DGEBA), epoxy resin (BE-188), and polyamine hardener (H2310 polyamine amide) were supplied by Mc-Growth Chem. GNP was purchased from XG Science 
Inc., East Lansing, USA with the specification of 6-10 layer graphene, 3.4- $7.0 \mathrm{~nm}$ and $50 \mu \mathrm{m}$ in thickness and diameter, respectively.

\section{Preparation of nanocomposites}

GNP filler was dispersed in ethanol (1:250 ratio) and subsequently sonicated using a sonicator ultrasonic Bilon-1200Y for 15 minutes. The suspension was then kept in the fume hood to evaporate the ethanol in order to reduce the formation of an air bubble on the coating surface. After that, the dispersion was added gradually into the epoxy resin and slowly stirred at $\sim 200 \mathrm{rpm}$ by a mechanical stirrer for 15 minutes. Finally, a stoichiometric amount of hardener with a weight ratio of 2:1 was added into the mixture and continuously stirred until the mixture was uniformly mixed. Various formulations of the epoxy-graphene nanocomposite are tabulated in Table 1. Welldispersed epoxy/nanoparticles filler mixture was then coated onto mild steel plates to form $\sim 0.25 \mathrm{~mm}$ thickness of coating samples using a doctor blade film applicator.

Table 1 Formulation of the EP-GNP nanocomposite coatings and their corresponding LOI values.

\begin{tabular}{lllll}
\hline \multirow{2}{*}{ Sample } & \multicolumn{3}{c}{ Composition (wt. \%) } & \multirow{2}{*}{ LOI (\%) } \\
\cline { 2 - 4 } & BE188 & Hardener & GNP & \\
\hline EG0 & 66.7 & 33.3 & 0.0 & 21.0 \\
EG1 & 66.7 & 33.3 & 0.2 & 22.0 \\
EG2 & 66.7 & 33.3 & 0.4 & 22.5 \\
EG3 & 66.7 & 33.3 & 0.6 & 22.5 \\
EG4 & 66.7 & 33.3 & 0.8 & 23.0 \\
EG5 & 66.7 & 33.3 & 1.0 & 24.0 \\
\hline
\end{tabular}

\section{Measurements}

Flame retardant properties of epoxy nanocomposites coatings were measured by limiting oxygen index (LOI) tests. LOI was measured according to ASTM D 2863 using Dynisco Instruments, USA). The specimens used for the test were of dimensions $80 \times 10 \times$ $3 \mathrm{~mm}^{2}$.

The thermal gravimetric analysis (TGA) measurement was conducted by the aid of a Perkin Elmer TGA/DSC at a thermal rate of $20{ }^{\circ} \mathrm{C} / \mathrm{min}$ in the range of $20-500{ }^{\circ} \mathrm{C}$. About $4-10 \mathrm{mg}$ of the samples were heated from room temperature to $900{ }^{\circ} \mathrm{C}$ at heating rate 10 ${ }^{\circ} \mathrm{C} /$ min under air temperature.

Corrosion study was observed by the salt spray test on scratched samples for 300 and $500 \mathrm{~h}$ exposure to an accelerated environment of salt fog chamber according to ASTMB117.

The interfacial adhesion between the coating and mild steel subtract plate was measured according to the ASTM-D3359 standard using an adhesion tape kit (PA-2000, Paul N. Gardner Company Inc., Florida, USA) with a standard blade (PA-2253 thick coatings).

The water absorption test was conducted according to the specifications of ASTM D570-98. The water uptake $\left(M_{t}\right)$ of the specimens was calculated by using the following formula:

$$
M_{t}=\frac{W_{t}-W_{0}}{W_{0}} \times 100 \%
$$

$M_{t}, W_{t}$ and $W_{0}$ are the moisture content at a given time, weight of the sample at the time of the measurement and initial weight, respectively. Fick's equation (Eq. 2) was used to calculate the coefficient of diffusion,

$$
\frac{\Delta M_{t}}{M_{o}}=\frac{\Delta M_{\infty}}{M_{o}} \sqrt{\frac{16 D}{\pi}} \frac{\sqrt{t}}{h}
$$

where $\Delta M_{t}(\mathrm{~g})$ is the amount of water absorbed by the film at time $\mathrm{t}(s)$, $M_{0}(\mathrm{~g})$ is the initial film mass, $\Delta M_{\infty}(\mathrm{g})$ is the amount of water absorbed at equilibrium, $D$ is the diffusion coefficient, and $h$ is the film thickness.

The distribution of nanoparticles fillers in the epoxy matrix was examined with an HRTEM $120 \mathrm{KV}$ Hi-Tech Instruments.

\section{RESULTS AND DISCUSSION}

\section{Limiting oxygen index}

The Limiting Oxygen Index (LOI) values of EP-GNP nanocomposite coatings are given in Table 1. Neat epoxy coating exhibited the LOI value of $21.0 \%$ and there was a gradual increase for EP-GNP samples which considered unlikely to support burning in atmospheric air (Bajaj, 1992). Epoxy resin has a tendency to spread flame away from a fire source. Liu et al. (2014) reported that the incorporation of very low content $(0.5$ wt. \% GNS) can effectively decrease the melt flow and inhibit the flammable drips of epoxy resin during combustion as well as can change the path of thermal degradation of epoxy resin. The present study indicated that the flame retardancy increased with the increase of GNP content. The LOI value reached 24.0 (increase by $14 \%$ relative to neat epoxy coating) with the incorporation of 1.0 wt. $\%$ of GNP indicating that their flammability was remarkably reduced due to the addition of GNP. This similar phenomenon was also observed in the previous report on $\mathrm{PET} / \mathrm{PP} / \mathrm{GNP}$ nanocomposite (Inuwa et al., 2014). The char formations from the LOI test are depicted in Fig. 1. It is apparent that the additional GNP produced more char when compared to neat epoxy coating.

\section{Thermal gravimetric analysis (TGA)}

The thermal stability of different EP-GNP nanocomposite coatings was investigated by TGA curve (Fig. 2a). It can be seen that all samples have a similar one-stage weight loss, indicating that they have a similar thermal degradation mechanism. The curves of all samples were similar at an initial temperature between 100 and 350 ${ }^{\circ} \mathrm{C}$ with weight loss less than $14 \%$ at $320{ }^{\circ} \mathrm{C}$. It can be seen that the inclusion of GNP has slightly shifted the degradation stage to a low temperature and induced the more stable char layer at high temperature. The residual weight of neat epoxy, GNP 0.2, 0.6, and 1.0 wt. $\%$ at $800{ }^{\circ} \mathrm{C}$ were $8.1,13.6,13.8$, and 14.0 wt. $\%$, respectively. The higher residual weight indicated that the incorporation of GNP induces an important thermal stabilization, resulting in good fire protection performance. This enhancement probably ascribed to the so-called "tortuous" path effect, which limits the entry of oxygen thus delaying the escape of volatile degradation products and also char formation (Prolongo et al., 2013, Wang et al., 2012, Kuilla et al., 2010). As illustrated in DTG curves (Fig. 2b), the thermal degradation of neat epoxy and EP-GNP nanocomposite coating are characterized by a single stage, indicating the addition of GNP has no influence on decomposition process. 

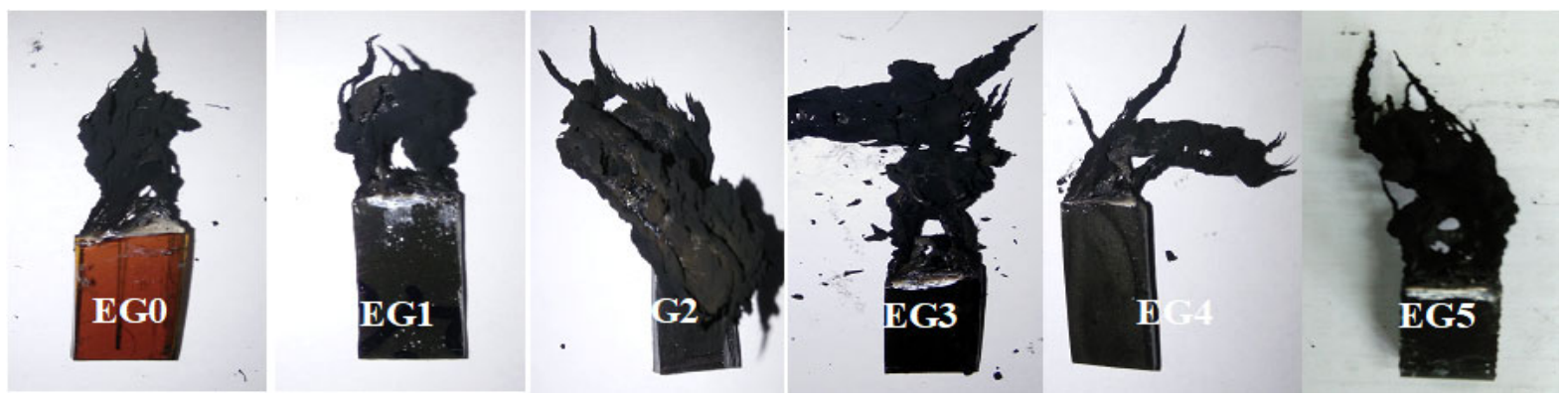

Fig. 1 Char residue of neat and EP-GNP samples after the LOI test.

(a)

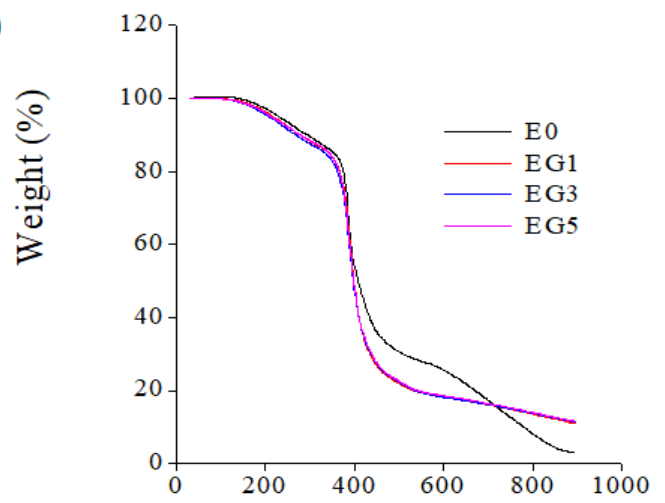

(b)

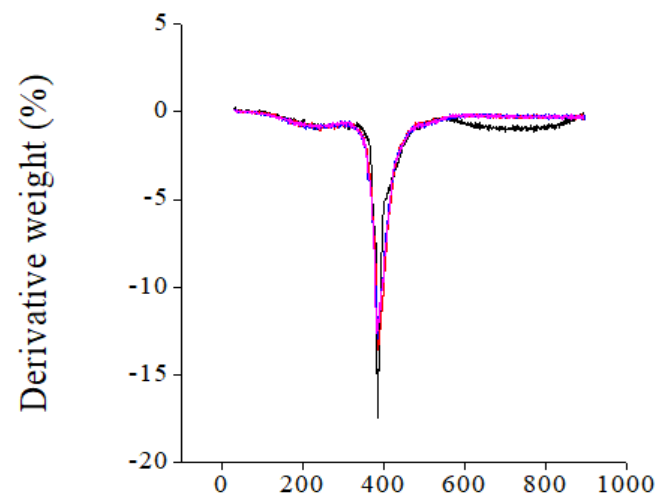

Temperature $\left({ }^{\circ} \mathrm{C}\right)$

Fig. 2 (a) TGA and (b) DTG thermogram of neat and EP-GNP samples.

\section{Salt spray test}

The salt spray test was conducted as an accelerated corrosion testing method by evaluating the rust, blister, cracking, and delamination along the coating's surface on the mild steel substrate. Fig. 3 shows the appearance of the surfaces of the EP-GNP nanocomposite coatings samples after 200 and 500 hours of salt spray for different GNP loading. A mild steel plate coated with neat epoxy system underwent severe corrosion compared to EP-GNP nanocomposite coating. Large blisters appeared nearby the scratches and over the whole coated surface in the neat epoxy coating sample with a brown adherent corrosion product (Fig. 3 (a)). Some rusting and blisters were observed on EG1, EG2, and EG3 coating surface after 200 hours of exposure, while, no blister was found in EG4 and EG5 samples. A previous study by Liu et al. (2016) revealed that superior anticorrosive performance was exhibited by coating with 0.5 wt. \% graphene. They concluded that the well-dispersed graphene blocks the coating pores and reduce the electrolyte diffusion toward the substrate, thus reduces the corrosion activity after exposure to salt spray.

Serious rusting appeared along the surface after 500 hours of exposure to salt spray test for EG0, EG1, and EG2 coatings with a diameter of rusts almost 2.0-2.5 mm (Fig. 3 (g), (h) and (i)). The yellow-brown rust and blistering appeared near the scratches and the bottom of the samples due to the poorest protection of the cut edges of the sample. Few rusts could be observed for EG3 and EG4 coatings (Fig. 3 (j) and (k)). Although the corrosion process has started to take effect on this topcoat as well, the blisters formed in this sample were very small (diameter between 1.0-1.5 mm). At $1.0 \mathrm{wt}$ \% EP-GNP content, anticorrosion performance started to decrease (Fig. 3 (1)). Graphene tends to agglomerate in the form of layers, by layer stacking due to the van der Waals interactions (Terrones et al., 2011) which then limit the barrier effect of nanofiller.

\section{Adhesion test}

Table 4 is tabulated to represent the adhesion test data for mild steel plate coated with neat and EP-GNP nanocomposite coatings after exposure to $5.0 \mathrm{wt} \% \% \mathrm{NaCl}$ solution. As expected, incorporation of GNP improved the adhesion (described as 5B) before immersion. The adhesion of neat epoxy coating showed $5 \mathrm{~B}$ adhesion strength and declined to $0 \mathrm{~B}$ after $200 \mathrm{~h}$ of exposure. The result showed that EG1 and EG2 samples were reduced in adhesion from $5 \mathrm{~B}$ to $1 \mathrm{~B}$, while EG3 and EG5 experienced a reduction to $2 \mathrm{~B}$. This might happened due to the penetration of electrolyte through coating pores and reach the metal surface which results in adhesion failure and initiating the electrochemical process on a metal surface (Hosseini et al., 2009; Zhou, 2011). In the present study, EG4 (0.8 wt. \% GNP) demonstrated the best adhesion properties with about 5 to $15 \%$ surface affected area of the lattice (adhesion at scale No.3B). Increasing graphene content in the epoxy matrix beyond an optimum loading $(0.5 \mathrm{wt}$. \%) resulted in the loss of interfacial adhesion bond (Alhumade et al., 2016) and the degree of dispersion was proportional to the graphene loading. Graphene is easily to aggregate together due to their strong van der Waals forces and high specific surface areas, which makes it difficult to achieve a homogeneous dispersion of graphene in a polymer matrix (Gu et al., 2015).

Table 2 Adhesion test result for neat and EP-GNP nanocomposite coatings after $200 \mathrm{~h}$ exposure to $5.0 \mathrm{wt}$. \% NaCl solution according to ASTM D3359.

\begin{tabular}{lcc}
\hline \multirow{2}{*}{ Samples } & \multicolumn{2}{c}{ Adhesion strength } \\
\cline { 2 - 3 } & Before exposure & After 200 h exposure \\
\hline EG0 & $5 \mathrm{~B}$ & OB \\
EG1 & $5 \mathrm{~B}$ & $1 \mathrm{~B}$ \\
EG2 & $5 \mathrm{~B}$ & $1 \mathrm{~B}$ \\
EG3 & $5 \mathrm{~B}$ & $2 \mathrm{~B}$ \\
EG4 & $5 \mathrm{~B}$ & $3 \mathrm{~B}$ \\
EG5 & $5 \mathrm{~B}$ & $2 \mathrm{~B}$ \\
\hline
\end{tabular}




\section{Water uptake test}

Corrosion performance of coating material is strongly affected by the water uptake which usually diminishes the adhesion of the coating and causes the delamination. Results indicated that the maximum water content absorbed of an EG0 coating was clearly higher compared to the other samples. This might be corresponded to the water molecules interact with polar groups (hydroxyl, amino) of epoxy network and the availability of microvoids (Nogueira et al., 2001) (Fig. 4a). Fig. 4b demonstrated that the diffusion coefficient of water $(D)$ after 154 days of immersion was decreased by incorporation of GNP due to the hydrophobic behavior of EP-GNP that denoted a higher chemical strength in humid environmental. In addition, the $D$ value increased abruptly from about $3.723 \times 10^{-8}$ to $7.098 \times 10^{-7}$ $\mathrm{mm}^{2} / \mathrm{s}$ for EG4 and EG5, respectively which might be associated with the poor dispersion and/or agglomeration of nanofillers in EG5 sample. This was in accordance with the result found in adhesion tape test.
Time (h)

EG0

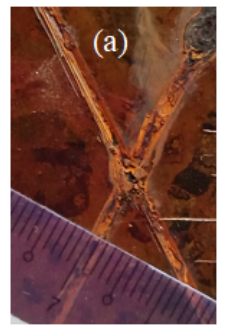

500

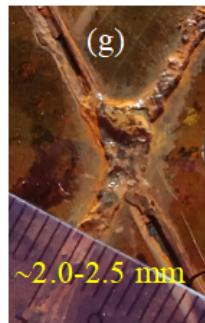

EG1
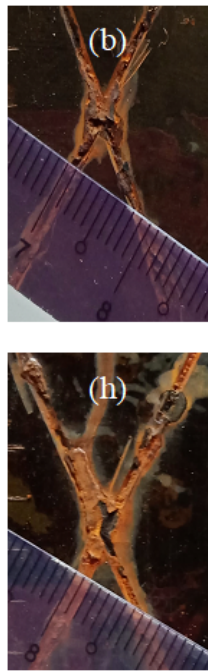

EG3
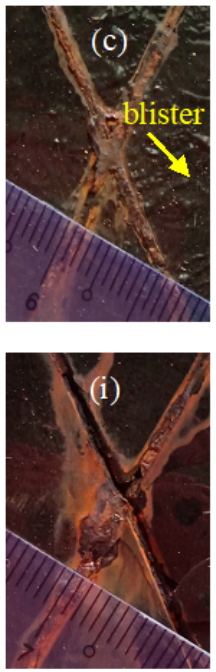

EG3
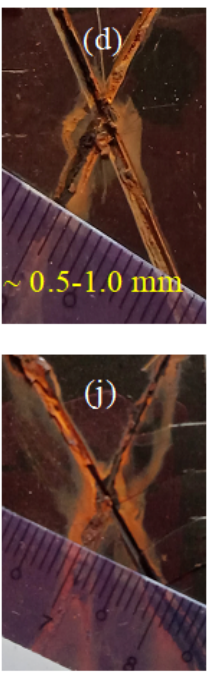

EG4
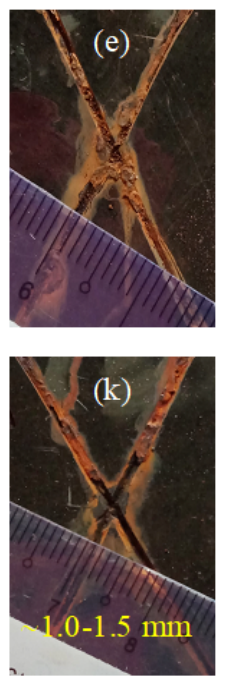

EG5
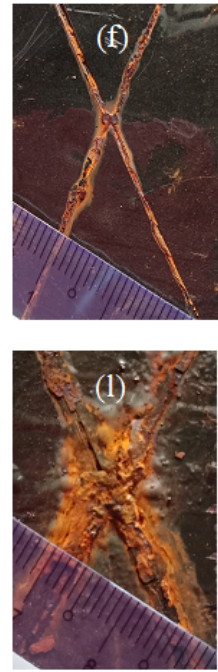

Fig. 3 Surfaces appearance of mild steel plate coated with neat and EP-GNP coatings at 200 and 500 hours of salt spray test.
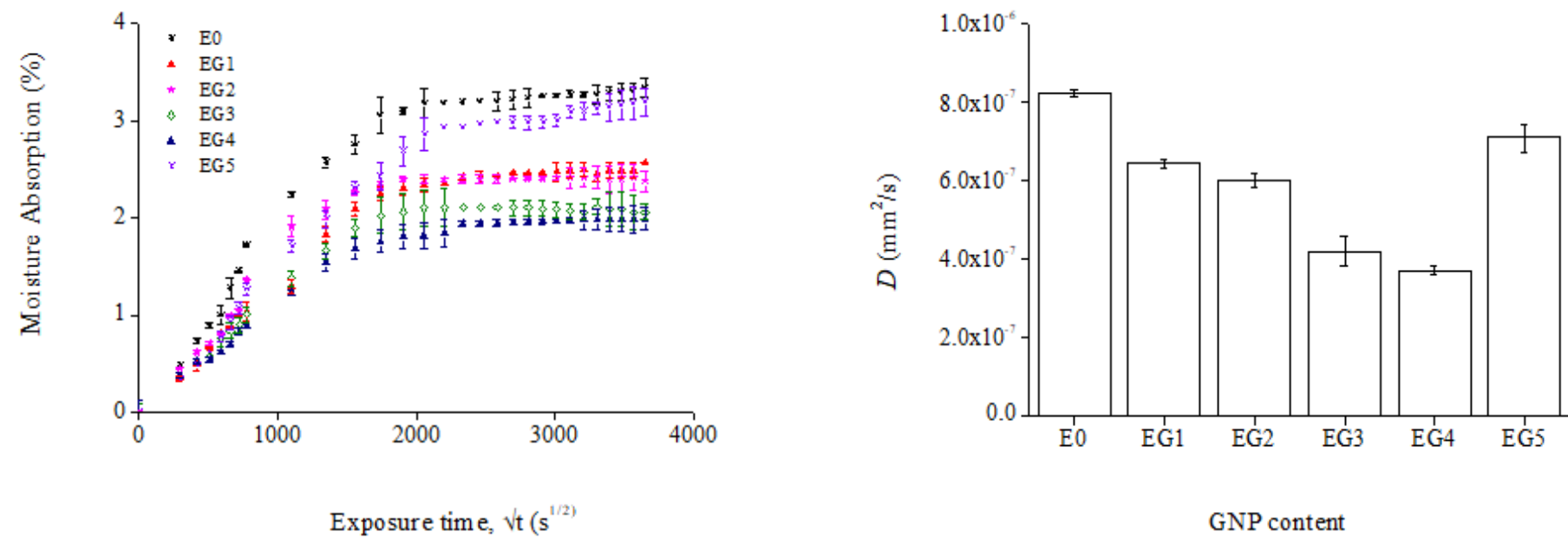

Fig. 4 (a) Water uptake (b) Diffusion coefficient of water $(D)$ for neat and EP-GNP coatings in water immersion at room temperature.

\section{Transmission electron microscopy (TEM)}

The dispersion of GNP fillers in epoxy nanocomposite coatings at the lowest and highest content is as shown in Fig. 5a and 5b. The presence of voids in the stacked nanoplatelets structures and large aggregate domains are clearly seen at higher GNP content (Fig 5b). Agglomerated GNP tend to form obstacles which hindered the flow of polymer into the agglomerates, hence resulting in the formation of holes and voids between GNP and epoxy (King et al., 2008; Zhang et al., 2013; Yue et al., 2014).
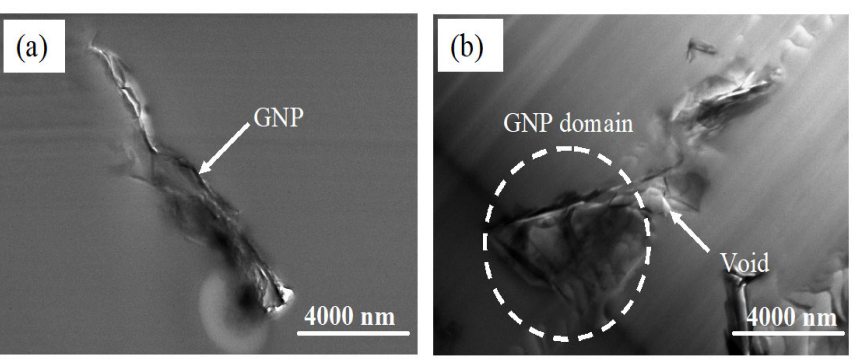

Fig. 5 TEM images of EP-GNP nanocomposite coatings: (a) 0.2 wt. \% GNP (b) 1.0 wt. \% GNP. 


\section{CONCLUSION}

The present study indicated that the incorporation of GNP nanoparticles filler enhanced the flame retardancy and expanded the durability of anticorrosion performance. LOI results showed that GNP enhanced the flammability properties and improved the char yield at $800{ }^{\circ} \mathrm{C}$ as well as decreasing the maximum weight loss rate, suggesting improved thermal stability. Results obtained from salt spray test revealed that additional GNP provided corrosion resistance against electrolyte diffusion with the greatest increase in corrosion resistance was observed for $0.8 \mathrm{wt}$. \% GNP content. The water uptake and coefficient diffusion confirmed that GNP might act as reservoirs for the storage and prolonged lease of corrosion inhibitor.

\section{ACKNOWLEDGEMENT}

The author would like to thank the Universiti Teknologi Malaysia (UTM) for funding this research under GUP grant No 12J81, 10H94, and $17 \mathrm{H} 66$.

\section{REFERENCES}

S. Pour-Ali, C. Dehghanian, A. Kosari. 2014. In situ synthesis of polyanilinecamphorsulfonate particles in an epoxy matrix for corrosion protection of mild steel in $\mathrm{NaCl}$ solution. Corrosion Science, 85, 204-214.

A. M. Atta, A. M. El-Saeed, G. M. El-Mahdy, H. A. Al-Lohedan. 2015. Application of magnetite nano-hybrid epoxy as protective marine coatings for steel. RSC Advances, 5, 101923-101931.

M. Popović, B. Grgur, V. Mišković-Stanković. 2005. Corrosion studies on electrochemically deposited PANI and PANI/epoxy coatings on mild steel in acid sulfate solution. Progress in Organic Coatings, 52, 359-365.

X. Zhang, F. Wang, Y. Du. 2007. Effect of nano-sized titanium powder addition on corrosion performance of epoxy coatings. Surface and Coatings Technology, 201, 7241-7245.

Y. Shao, C. Jia, G. Meng, T. Zhang, F. Wang. 2009. The role of a zinc phosphate pigment in the corrosion of scratched epoxy-coated steel. Corrosion Science, 51, 371-379.

C. Chen, S. Qiu, M. Cui, S. Qin, G. Yan, H. Zhao, L. Wang, Q. Xue. 2017. Achieving high performance corrosion and wear resistant epoxy coatings via incorporation of noncovalent functionalized graphene. Carbon, 114, 356-366.

G. Shi, M. Q. Zhang, M. Z. Rong, B. Wetzel, K. Friedrich. Friction and wear of low nanometer Si 3 N 4 filled epoxy composites. 2003. Wear, 254, 784796.

A. Hartwig, M. Sebald, D. Pütz, L. Aberle. 2005. Preparation, characterisation and properties of nanocomposites based on epoxy resins. Macromolecular Symposia, 221, 127-135.

R. Raccichini, A. Varzi, S. Passerini, B. Scrosati. 2015. The role of graphene for electrochemical energy storage. Nature materials, 14, 271-279.

H. Xia, C. Hong, B. Li, B. Zhao, Z. Lin, M. Zheng, S.V. Savilov, S. M. Aldoshin. 2015. Facile synthesis of hematite quantum-dot/functionalized graphene-sheet composites as advanced anode materials for asymmetric supercapacitors. Advanced Functional Materials, 25, 627-635.

G. Mittal, V. Dhand, K. Y. Rhee, S.-J. Park, W. R. Lee. 2015. A review on carbon nanotubes and graphene as fillers in reinforced polymer nanocomposites. Journal of Industrial and Engineering Chemistry, 21, 1125.

S. K. Vashist, J. H. T. Luong. 2015. Recent advances in electrochemical biosensing schemes using graphene and graphene-based nanocomposites. Carbon, 84, 519-550.

D. Prasai, J. C. Tuberquia, R. R. Harl, G.K. Jennings, K. I. Bolotin. 2012. Graphene: corrosion-inhibiting coating. ACS Nano, 6, 1102-1108.

N. T. Kirkland, T. Schiller, N. Medhekar, N. Birbilis. Exploring graphene as a corrosion protection barrier. Corrosion Science, 56 (2012) 1-4.
C.-H. Chang, T.-C. Huang, C.-W. Peng, T.-C. Yeh, H.-I. Lu, W.-I. Hung, C.-J. Weng, T.-I. Yang, J.-M. Yeh. 2012. Novel anticorrosion coatings prepared from polyaniline/graphene composites. Carbon, 50, 5044-5051.

F. Zhou, Z. Li, G.J. Shenoy, L. Li, H. Liu. 2013. Enhanced room-temperature corrosion of copper in the presence of graphene. ACS Nano, 7, 6939-6947.

Y.-H. Yu, Y.-Y. Lin, C.-H. Lin, C.-C. Chan, Y.-C. Huang. 2014. Highperformance polystyrene/graphene-based nanocomposites with excellent anti-corrosion properties. Polymer Chemistry, 5, 535-550.

S. Chen, L. Brown, M. Levendorf, W. Cai, S.-Y. Ju, J. Edgeworth, X. Li, C.W. Magnuson, A. Velamakanni, R. D. Piner. 2011. Oxidation resistance of graphene-coated $\mathrm{Cu}$ and $\mathrm{Cu} / \mathrm{Ni}$ alloy. ACS Nano, 5, 1321-1327.

J. S. Bunch, S. S. Verbridge, J. S. Alden, A. M. Van Der Zande, J. M. Parpia, H. G. Craighead, P. L. McEuen. 2008. Impermeable atomic membranes from graphene sheets. Nano Letters, 8, 2458-2462.

H. Alhumade, A. Yu, A. Elkamel, L. Simon, A. Abdala. 2016. Enhanced protective properties and UV stability of epoxy/graphene nanocomposite coating on stainless steel. Express Polymer Letters, 10(12), 1034-1046.

P. Bajaj. 1992. Fire-retardant materials. Bulletin of Materials Science, 15, 6776.

S. Liu, H. Yan, Z. Fang, H. Wang. 2014. Effect of graphene nanosheets on morphology, thermal stability and flame retardancy of epoxy resin. Composites Science and Technology, 90, 40-47.

I. M. Inuwa, A. Hassan, D.-Y. Wang, S. A. Samsudin, M. K. Mohamad Haafiz, S. L. Wong, M. Jawaid. 2014. Influence of exfoliated graphite nanoplatelets on the flammability and thermal properties of polyethylene terephthalate/polypropylene nanocomposites. Polymer Degradation and Stability, 110, 137-148.

S. G. Prolongo, A. Jimenez-Suarez, R. Moriche, A. Ureña. 2013. In situ processing of epoxy composites reinforced with graphene nanoplatelets. Composites Science and Technology, 86, 185-191.

X. Wang, W. Xing, P. Zhang, L. Song, H. Yang, Y. Hu. 2012. Covalent functionalization of graphene with organosilane and its use as a reinforcement in epoxy composites. Composites Science and Technology, 72, 737-743.

T. Kuilla, S. Bhadra, D. Yao, N.H. Kim, S. Bose, J. H. Lee. 2010. Recent advances in graphene-based polymer composites. Progress in Polymer Science, 35, 1350-1375.

S. Liu, L. Gu, H. Zhao, J. Chen, H. Yu. 2016. Corrosion Resistance of graphene-reinforced waterborne epoxy coatings. Journal of Materials Science \& Technology, 32, 425-431.

M. Terrones, O. Martín, M. González, J. Pozuelo, B. Serrano, J. C. Cabanelas, S. M. Vega-Díaz, J. Baselga. 2011. Interphases in Graphene polymerbased nanocomposites: Achievements and challenges. Advanced Materials, 23, 5302-5310.

M. G. Hosseini, M. Raghibi-Boroujeni, I. Ahadzadeh, R. Najjar, M. S. Seyed Dorraji. 2009. Effect of polypyrrole-montmorillonite nanocomposites powder addition on corrosion performance of epoxy coatings on Al 5000. Progress in Organic Coatings, 66, 321-327.

X. Zhou. 2011. Graphene oxidation barrier coating. An Undergraduate Honor's Thesis, University of Colorado at Boulder.

L. Gu, S. Liu, H. C. Zhao, H. B. Yu. 2015. Facile preparation of waterdispersible graphene sheets stabilized by carboxylated oligoanilines and their anticorrosion coatings. ACS Applied Materials \& Interfaces, 7, 17641-17648.

P. Nogueira, C. Ramirez, A. Torres, M. J. Abad, J. Cano, J. Lopez, I. López-Bueno, L. Barral. 2001. Effect of water sorption on the structure and mechanical properties of an epoxy resin system. Journal of Applied Polymer Science, 80, 71-80.

J. A. King, R. L. Barton, R. A. Hauser, J. M. Keith. 2008. Synergistic effects of carbon fillers in electrically and thermally conductive liquid crystal polymer-based resins. Polymer Composites, 29, 421-428.

X. Zhang, O. Alloul, Q. He, J. Zhu, M. J. Verde, Y. Li, S. Wei, Z. Guo. 2013. Strengthened magnetic epoxy nanocomposites with protruding nanoparticles on the graphene nanosheets. Polymer, 54, 3594-3604.

L. Yue, G. Pircheraghi, S. A. Monemian, I. Manas-Zloczower. 2014. Epoxy composites with carbon nanotubes and graphene nanoplatelets-Dispersion and synergy effects. Carbon, 78, 268-278. 